\title{
Spatial Distribution Simulation and Trend Analysis of Land Use in Sanya Based on GeoSOS-FLUS Model
}

\author{
Jian Kai ${ }^{1,2, ~ *, ~ W a n g ~ S h e n g n a n ~}{ }^{1}$, Guo Lixia ${ }^{2}$, Zhang Qing ${ }^{1}$ \\ ${ }^{1}$ School of Art, Sanya University, Sanya, China \\ ${ }^{2}$ School of Architecture, Inner Mongolia University of Technology, Hohhot, China
}

Email address:

928745785@qq.com (Jian Kai)

${ }^{*}$ Corresponding author

To cite this article:

Jian Kai, Wang Shengnan, Guo Lixia, Zhang Qing. Spatial Distribution Simulation and Trend Analysis of Land Use in Sanya Based on GeoSOS-FLUS Model. Urban and Regional Planning. Vol. 5, No. 4, 2020, pp. 97-108. doi: 10.11648/j.urp.20200504.11

Received: October 29, 2020; Accepted: November 9, 2020; Published: November 19, 2020

\begin{abstract}
In the new era, with the acceleration of the construction of Hainan Free Trade Island, the contradiction between the maintenance of ecological security and the development of urban and rural construction in Sanya has become increasingly prominent. In order to explore the spatial pattern and sustainable development trend of land use in Sanya City in the future, this study uses the GeoSOS-FLUS model as the main model, ENVI remote sensing image interpretation and ArcGIS spatial analysis as the supplement, and Fragastas landscape pattern index analysis as the supplement to realize the spatial layout simulation and diversity evaluation of land use in Sanya City in the future. The land use circulation trend, fragmentation trend and diversity trend in Sanya from 2017 to 2025 were analyzed, and the regulation and guidance strategies of land use were discussed from three aspects of land space planning control, land landscape pattern control and land use circulation control. The results show that under the strict land use conversion restrictions, the degree of fragmentation of the land system in Sanya is generally decreased, and it maintains a relatively stable integrity, diversity and uniformity of the land system.
\end{abstract}

Keywords: Spatial Distribution, Development Trend, Land Use, GeoSOS-FLUS, Sanya City

\section{Introduction}

Land, as a spatial element with both expansion and obstruction, is one of the important spatial elements to determine whether a region can achieve sustainable development. In the new era, the construction of China's Hainan free trade island is in full swing, as the central city of southern Hainan province, Sanya city in the process of free trade island construction will face the contradiction between ecological security maintenance and urban and rural construction and development of increasingly prominent problems. In order to explore the spatial development trend of land use in Sanya City in the future, analyze the development policy of land use, and conduct a special literature review on the future simulation of land use. The review results show that: (1) Land use change, pattern change, land structure and spatial layout are the main contents of land use simulation research. Land use simulation is usually based on satellite remote sensing data, supplemented by data such as planning results and economic and social development. Through the formulation of transformation matrix and the selection of land use transformation driving factors, combined with the application of CLUE-S model, system dynamics model and ANN-CA model, the natural development scenario simulation, ecological security scenario simulation and ecological optimization scenario simulation of land use at the levels of structural pattern change and spatial distribution change are realized [1-3]. (2) The diversity of land use simulation method is an important embodiment of the complex factors of land use change. There are various methods to simulate the future development of land use, but the factors affecting the development of land use are complex. Land use change is mainly affected by natural, social, economic, environmental and other factors. Land use change research based on remote sensing data interpretation usually needs to develop specific conversion matrix and select specific land use conversion driving factors in the process of future land use change. In land use simulation, Tian Yichao, Zhao Xiaoquan, Gu Liuyang and Zhang Zhipeng used land use transition probability matrix, 
binary logistic regression model, land use change map, standard deviation ellipse, artificial neural network and cellular automata (ANN-CA) model, Logistic-CA-Markov coupling model to simulate and predict the structure of land use, and revealed the main control factors of land use change [4-8]. (3) Multi-situation simulation of land use is the scientific basis for the selection of land use development plan and the optimal policy of land development. In order to solve the problem of matching the allocation of urban land resources and the requirements of economic construction to the greatest extent, and to achieve the goal of maximizing the comprehensive benefit of urban land use, Yang Jianxin, Zhang Hanbing, Hao Xiaojing and others selected elevation, population, economy, temperature, precipitation and other factors as the driving factors, through the formulation of the cell transformation rules as the representative of the land use transformation rules, the LSSVM-CA model and CLUE-S model were used to simulate the land use change [9-11]. Tian Tongyu combined with the characteristics of land use structure and layout change, through the CLUE-S model application, the land use optimization scheme of multi-situation simulation, and determine the best scheme of land use, and ultimately realize the sustainable development of land use [12]. (4) Land use simulation research is an important reference and basis for realizing the sustainable development planning, management and implementation of regional land use. Ruan Junjie, Su Jinghua, Cao Qing et al, based on the CLUE-S model, combined with the control requirements of regional master plan and ecological protection red line, from the minimum cumulative resistance model, the ecological resistance expansion and spatial-temporal change pattern of land use were simulated, and the future change trend of land use was explained [13, 14]. Li Xianjiang, Shi Shuqin and Gong Wenfeng et al. used RS and GIS platforms to discuss the temporal and spatial evolution law and characteristics of land use pattern through the application of remote sensing data of land use. CA-Markov model was used to reasonably predict the future pattern of land use, and the simulation accuracy was tested $[15,16]$. Hu Zongnan, Li Xin, and He Ling et al. used remote sensing, meteorological data and field survey data, net primary productivity of vegetation, system dynamics model, cellular automata and Markov model to simulate the future land use structure and ecological security pattern $[17,18]$. These research results are aimed at realizing the research on rational utilization of land use and sustainable development by revealing the future trend of land use change, exploring the ecological security pattern, and proposing land use optimization and remediation strategies. In summary, the simulation of land use should focus on the driving factors affecting land use transformation, which is also the key to the scientific of the simulation results. In view of this, this study in Sanya City in the future land use layout simulation process, on the basis of emphasizing the rationality and scientific selection of land use conversion driving factors, through the simulation of land use in Sanya City to analyze the trend of sustainable development.

\section{Overview of Research and Data Sources}

\subsection{Introduction to Sanya}

Sanya is located in the south of Hainan Province, China. It is an important construction center city of Hainan Free Trade Demonstration Zone and a core city in the south of Hainan Province. It is also the only tropical coastal tourism city in China. Sanya is located in the hills and mountains to the north and the sea to the south. Its terrain is high in the north and low in the south. Its natural resources and humanistic resources are very rich. Its ecological living environment is good and belongs to the tropical marine monsoon climate.

\subsection{Source of Data}

The spatial data used in this study mainly come from the geospatial data website (http://www.gscloud.cn), mainly including Landsat 8 OLI remote sensing images and DEM data with $30 \mathrm{~m}$ spatial resolution. Among them, Landsat 8 OLI remote sensing image mainly selects the influence data of summer period in 2013 and 2017. The image is corrected by ENVI 5.2 software platform for radiometric calibration, atmospheric correction and image enhancement function. Then the remote sensing satellite map of Sanya City is extracted with the cutting tool. Combined with Chinese Remote Sensing Interpretation Standard and Overall Land Use Planning of Sanya (2006-2020), the remote sensing data is interpreted as six types of land landscape, including forest land, cultivated land, garden land, grassland, construction land, water and other land, and it is used as the initial value of land and the test value of simulation results to simulate the future land use development trend of Sanya City. DEM data are used to extract the natural driving factors of land use transformation in Sanya, including grid information such as elevation, slope, aspect and topographic index. In addition, the researchers also selected the data of population, GDP, transportation location, urban location and spatial distribution of construction activities in Sanya in 2013 as the social driving factors of land use transformation in Sanya. So as to realize the system construction and data collection of driving factors of land use transformation in Sanya.

\section{Research Methods and Technical Route}

\subsection{Methods}

The purpose of this study is to simulate the development trend of future land use in Sanya. GeoSOS-FLUS model is used as the main method, ENVI remote sensing image interpretation and ArcGIS spatial analysis are used as the auxiliary method, and Fragastas landscape pattern index analysis is used as the supplementary method to realize the spatial layout simulation and diversity evaluation of future land use in Sanya. Among them, the application of GeoSOS-FLUS model is mainly used to 
simulate the spatial distribution of land use, ENVI 5.2 is used to interpret the remote sensing data of Sanya in 2013 and 2017, ArcGIS 10.2.2 is used to analyze and extract the natural and social driving factors of land use transformation, and the application of Fragastas 4.2 can be used to extract the landscape pattern index of land use.

\subsection{Technical Route}

The expansion effect of urban and rural construction development and the obstruction effect of ecological security maintenance are the fundamental thrust of land use change. Taking 'spatial distribution extraction $\rightarrow$ spatial distribution simulation $\rightarrow$ development trend analysis' as the technical route, the future spatial distribution of land use is simulated by using GeoSOS-FLUS model, and it is emphasized that natural and social driving factors are the key forces to promote land use change (Figure 1). The details are as follows:

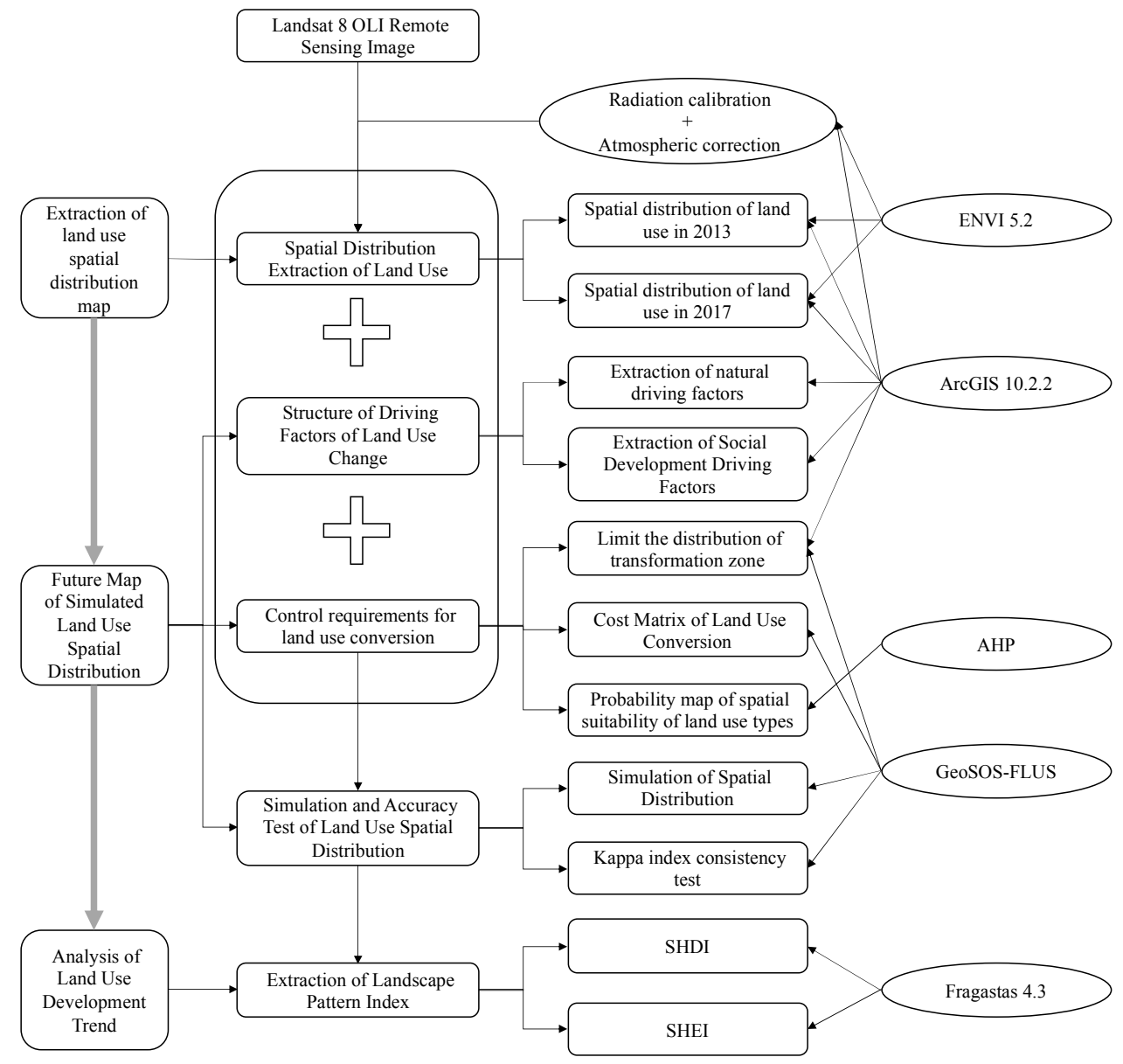

Figure 1. The technical route of land use spatial distribution simulation and trend analysis.

(1) Spatial distribution extraction. extraction of land use spatial distribution map is not only the basis of land use development simulation, but also an important basis to verify the accuracy of land use simulation results. Therefore, the researchers use Landsat 8 OLI remote sensing image as the basic data, using radiation calibration, atmospheric correction, image enhancement and other tools for image preprocessing, combined with ENVI5.2 software monitoring classification tools will be divided into six types of construction land, Unused land, water zone, woodland, cultivated land and grassland, so as to interpret the spatial distribution of land use status map (Figure 2), to provide basic data support for the spatial distribution of future land use simulation and testing. (2) Spatial distribution simulation. the role of driving factors and the probability of land conversion are the root causes of regional land use change. The development of urban and rural construction is the manifestation of changes in the spatial distribution of land use, and it is also the result of the action of natural driving factors and social driving factors, which determines the transformation direction and possibility of different types of land use. In other words, when simulating the spatial distribution of land use, it is necessary to formulate specific land use transformation matrix, transformation probability and transformation limitation according to the characteristics of regional development and policy requirements, so as to realize the scientific of the simulation results. (3) Development trend analysis. ecology is a main characteristic of land, and its ecological trend change is an important embodiment of sustainable development of land use. Through the application of Fragstas, the aromatic diversity index and aromatic uniformity index were extracted to analyze the ecological development trend of the future land use in 
Sanya, which is the root cause of the spatial distribution simulation of land use in this study.

\section{Results and Analysis}

\subsection{Simulation of Land Use Change}

\subsubsection{Prediction of Expansion Potential}

Land use change is a nonlinear complex process driven by many factors such as population, economy, transportation, urban development and natural conditions, These driving factors have the function of determining the development trend of land use spatial distribution. Based on the land use status map interpreted by the remote sensing data of Sanya in 2013 and 2017, the researchers used the neural network algorithm (ANN) to integrate nine driving factors such as elevation, slope, aspect, topographic coefficient, population, GDP, distance to the urban center, distance to the regional transportation network and spatial distribution of human activities, and calculated the probability map of the occurrence of various types of land use in each pixel in Sanya to characterize the spatial distribution trend of various types of land use in Sanya in the future, which is also an intuitive manifestation of the potential of various types of land expansion (Table 1, Figure 3-Figure 5).

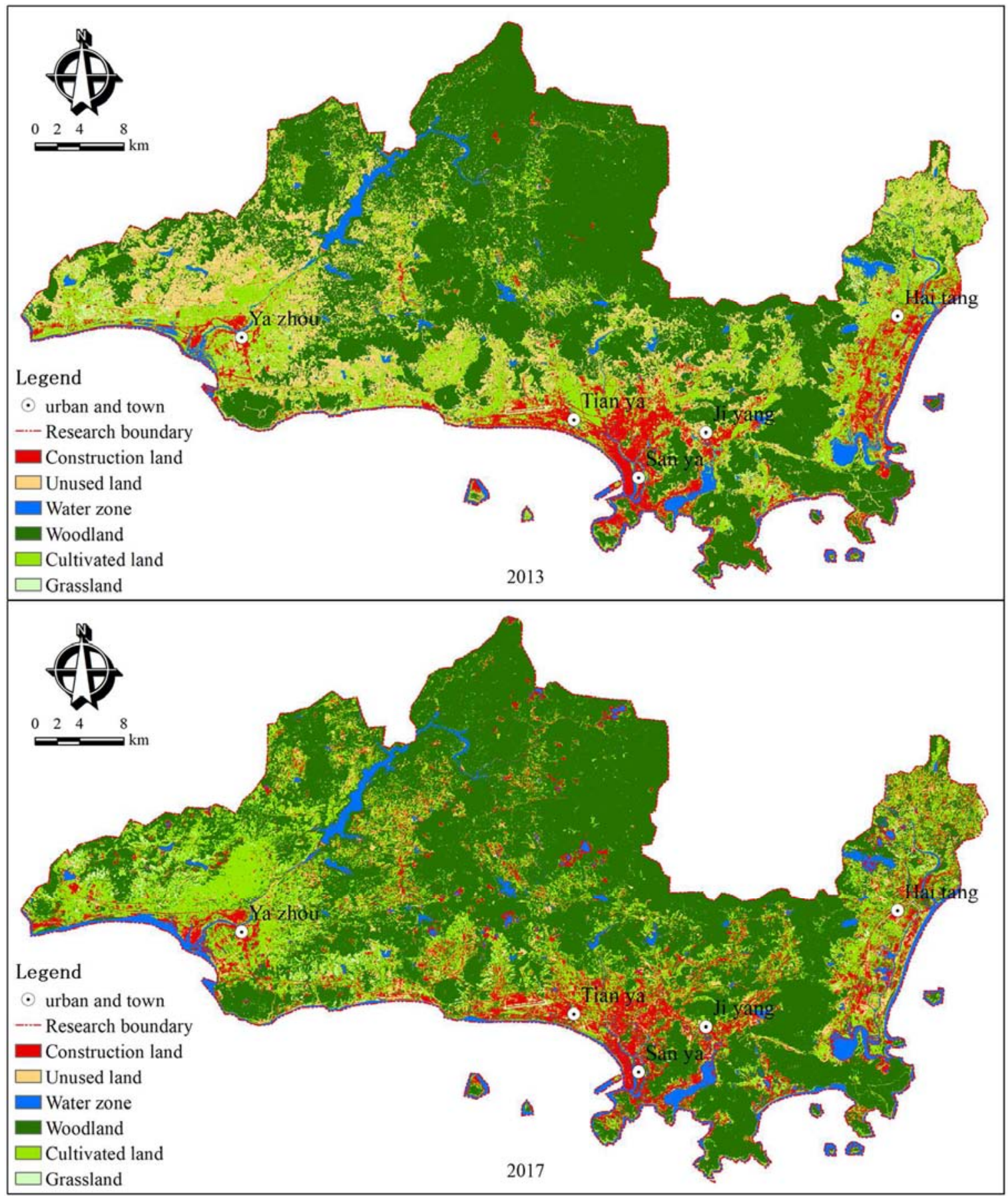

Figure 2. Spatial distribution of land use in 2013 and 2017. 


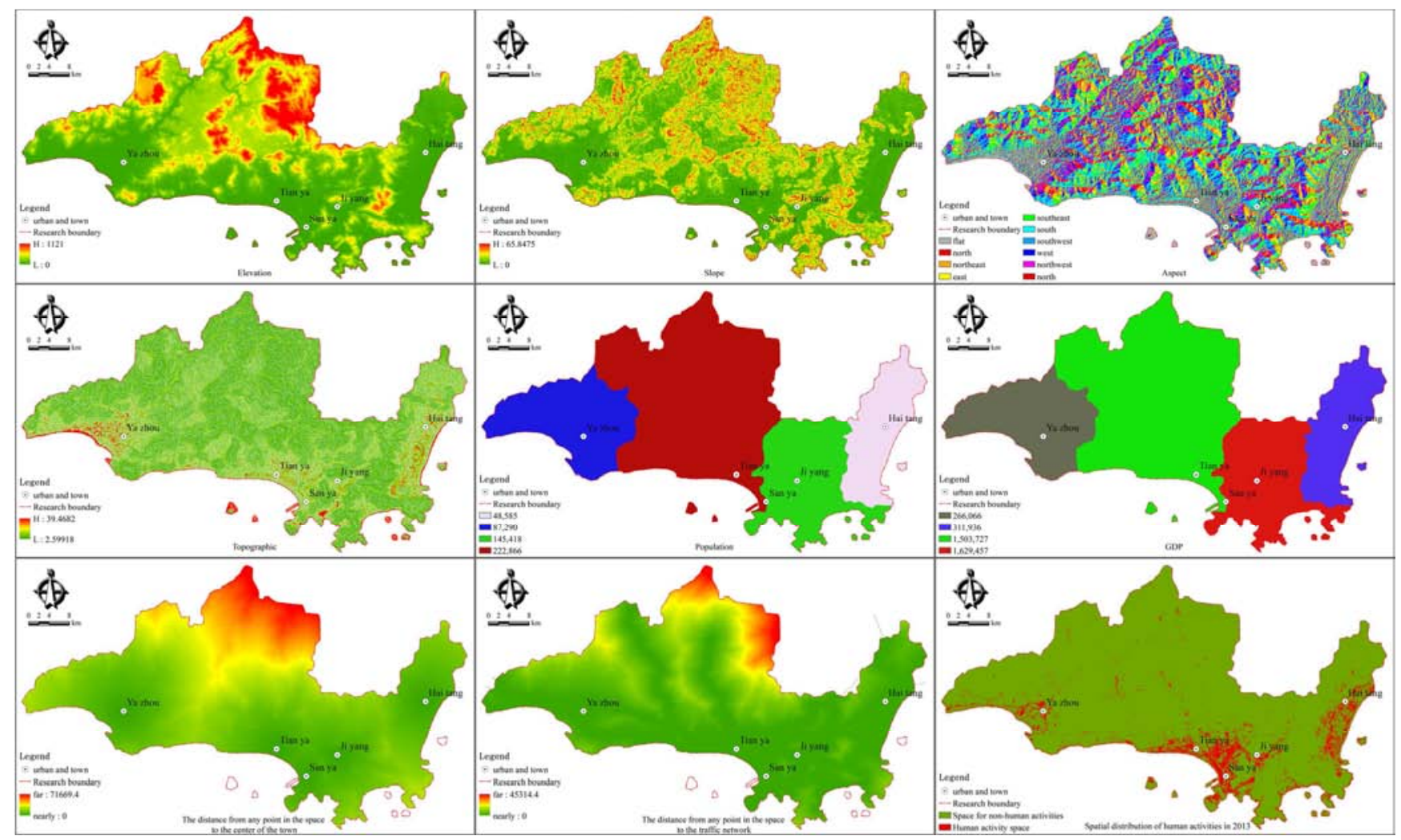

Figure 3. Composition of driving factors of land use change.

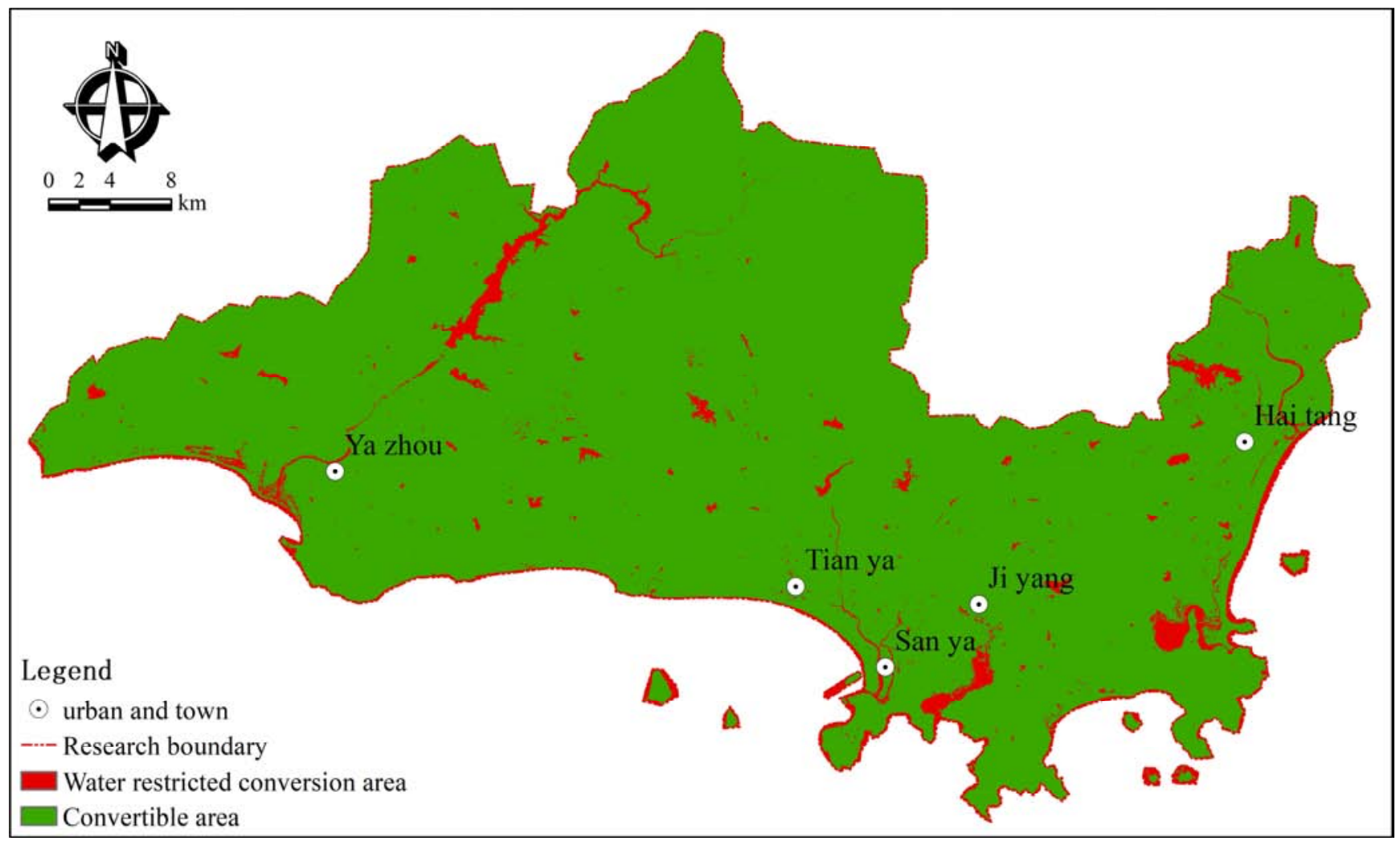

Figure 4. Spatial distribution of restricted transformation zone. 


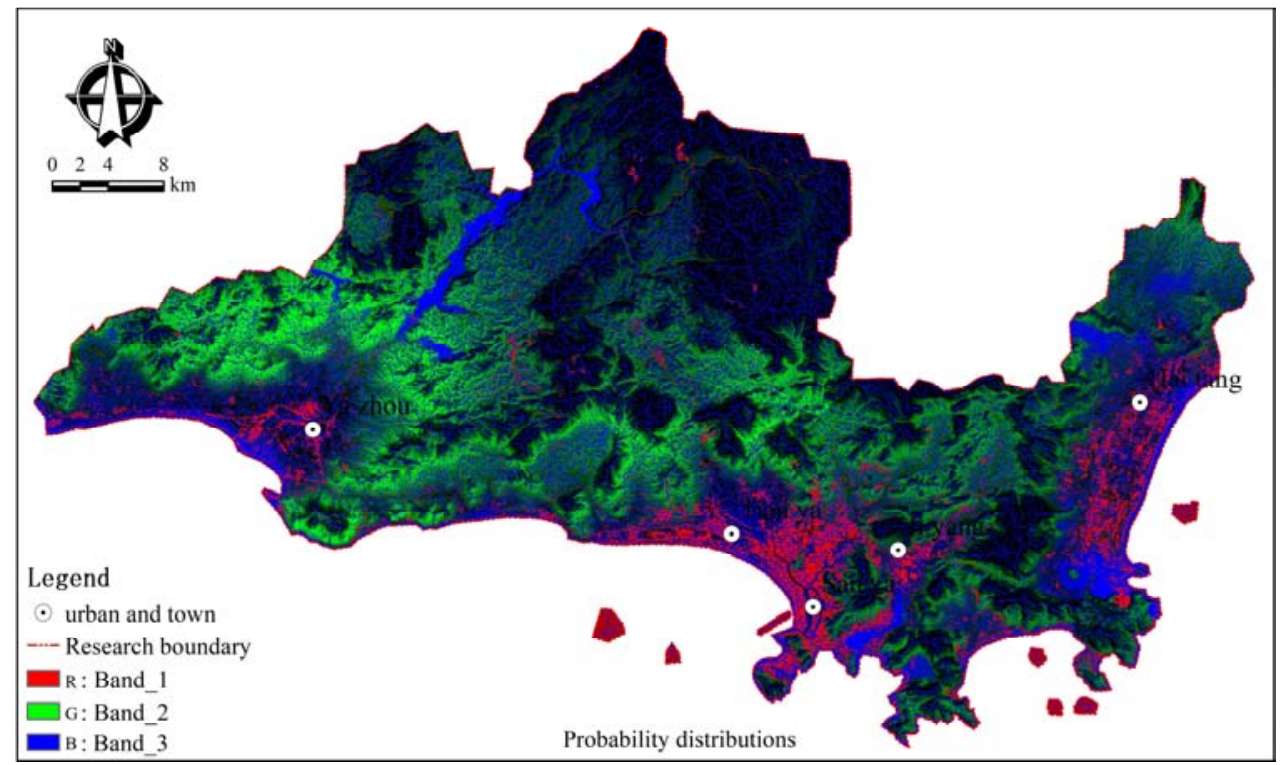

Figure 5. Spatial suitability probability of land use types.

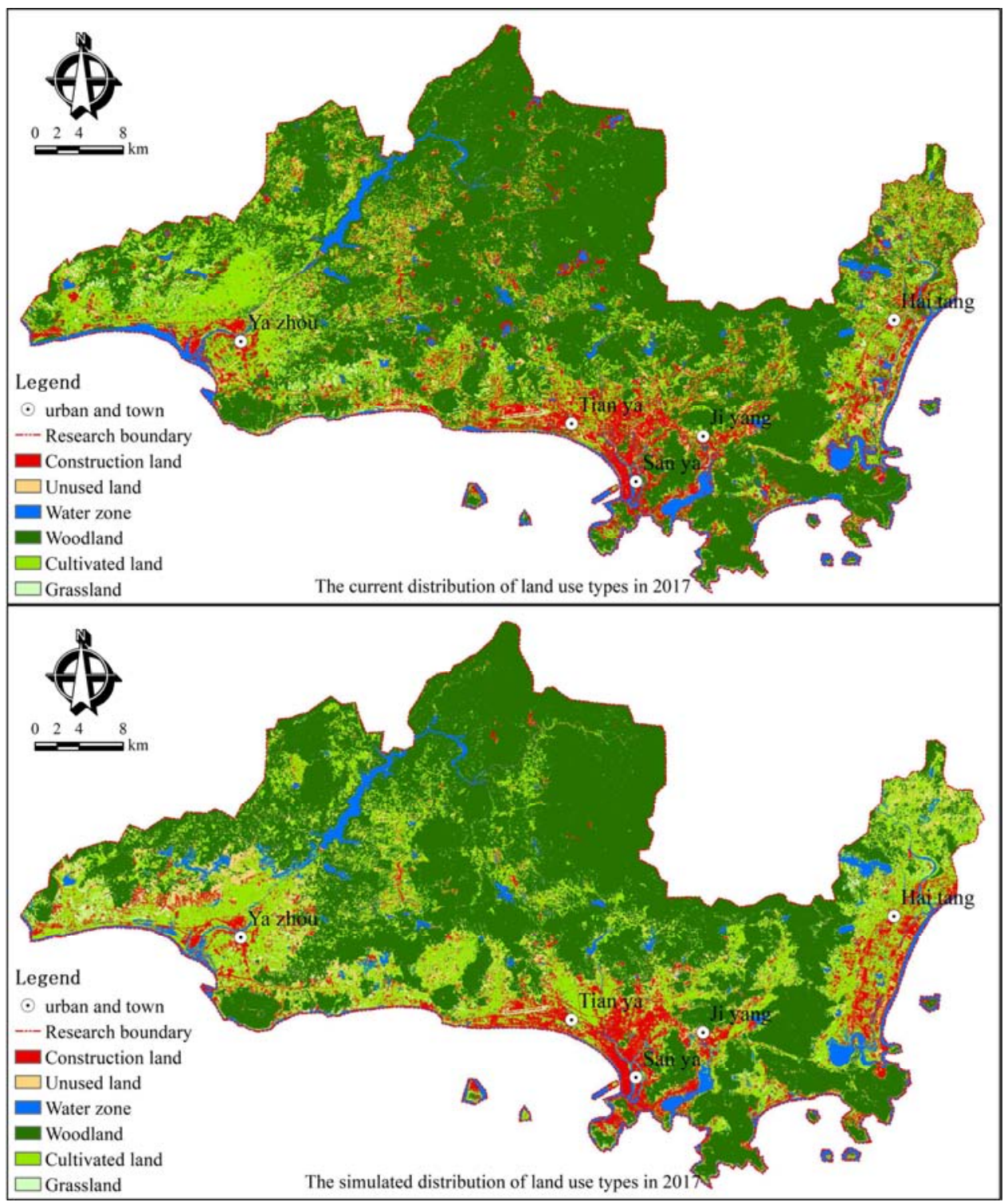

Figure 6. Status and Simulation of Spatial Distribution of Land Use in 2017. 


\subsubsection{Parameter Calculation}

Parameter estimation mainly includes three aspects: total demand, cost matrix and domain weight. (1) Total demand. Based on the remote sensing interpretation data of Sanya in 2013 and 2017, the demand for various types of land use in 2021 and 2025 was calculated by Markov chain module (Table 2). (2) Cost matrix. The application of cost matrix is a land use transformation rule proposed to adapt to local land use policies, which is a mathematical method to show the direction of land transfer. Among them, 0 represents a higher cost of land conversion, land expansion potential is small; 1 represents lower cost of land conversion and greater potential for land expansion. Based on the land use transfer matrix from 2013 to 2017 (Table 3), combined with the land development policy of Sanya City, the final cost matrix of land use change was determined (Table 4). (3) Domain weight. All kinds of land have different probability of land change in the process of land transfer, and the expansion probability of different land use types is different. In this study, the weights of construction land, Unused land, water zone, woodland, cultivated land and grassland were set to 1.0, $0.3,1.0,1.0,1.0$ and 0.1 by using AHP method.

\subsubsection{Precision Calculation}

In order to ensure the reliability of simulation results, the application of cellular automata model based on adaptive inertia competition is studied. Under the random sampling level of $10 \%$, the actual map and simulation map of spatial distribution of land use types in 2017 are selected for accuracy test (Figure 6). In the method, Kappa index was used to measure the consistency and accuracy between the simulation results of land use spatial distribution and the actual distribution. In order to reduce the mathematical calculation process of Kappa index, the precision validation module in the GeoSOS-FLUS model was used to calculate the Kappa index, and the accuracy of the simulation results was determined according to the range of Kappa index. The results show that the Kappa coefficient of land use spatial distribution simulation map of Sanya City in 2017 is 0.890365 , and its model accuracy is very high, which meets the research needs (Table 5).

Table 1. Function Description of Driving Factors of Land Use Change.

\begin{tabular}{|c|c|c|c|c|}
\hline Type & & Factor & Function description & Data description \\
\hline \multirow{4}{*}{$\begin{array}{l}\text { Driving } \\
\text { factor }\end{array}$} & $\begin{array}{l}\text { Natural } \\
\text { attributes }\end{array}$ & $\begin{array}{l}\text { Elevation } / \mathrm{m} \\
\text { Slope } / \% \\
\text { Aspect } /{ }^{\circ} \\
\text { Topographic index }\end{array}$ & $\begin{array}{l}\text { Vegetation in different elevation areas presents different } \\
\text { vegetation richness due to the influence of temperature } \\
\text { Different slope areas have different suitability intensity } \\
\text { The efficiency of different slope to accept sunlight is different } \\
\text { Hydrological sensitivity in different catchment areas }\end{array}$ & Calculated from DEM data \\
\hline & \multirow{3}{*}{$\begin{array}{l}\text { Social } \\
\text { development } \\
\text { attributes }\end{array}$} & $\begin{array}{l}\text { Population } / 10000 \\
\text { people }\end{array}$ & $\begin{array}{l}\text { Measuring the Impact of Population Density on Land Use } \\
\text { Change }\end{array}$ & $\begin{array}{l}\text { Total population in } \\
\text { administrative areas for } 2013\end{array}$ \\
\hline & & Location of Traffic/m & Measuring the Impact of Traffic Location on Land Use Change & $\begin{array}{l}\text { Distance from any point in } \\
\text { space to traffic network }\end{array}$ \\
\hline & & Human activity space & Space scope reflecting human activities & $\begin{array}{l}\text { Spatial distribution of } \\
\text { construction land in } 2013\end{array}$ \\
\hline
\end{tabular}

Table 2. Total land demand pixels.

\begin{tabular}{|c|c|c|c|c|c|c|}
\hline Year & Construction land & Unused land & Water zone & Woodland & Cultivated land & Grassland \\
\hline 2017 & 189158 & 108051 & 114755 & 1198164 & 516563 & 32835 \\
\hline 2021 & 198498 & 36355 & 119095 & 1204834 & 567860 & 32883 \\
\hline 2025 & 201640 & 12232 & 120555 & 1183276 & 609155 & 32667 \\
\hline
\end{tabular}

Remarks: The size of each pixel is $30 * 30$, that is, the area of a pixel is $900 \mathrm{~m}^{2}$.

Table 3. Conversion Matrix of Land Use in Sanya City from 2013 to 2017.

\begin{tabular}{|c|c|c|c|c|c|c|c|}
\hline Land use types & Construction land & Unused land & Water zone & Woodland & Cultivated land & Grassland & total \\
\hline Construction land & 161399 & 0 & 0 & 0 & 0 & 0 & 161399 \\
\hline Unused land & 27759 & 108051 & 12899 & 125553 & 45687 & 1189 & 321138 \\
\hline Water zone & 0 & 0 & 101856 & 0 & 0 & 0 & 101856 \\
\hline Woodland & 0 & 0 & 0 & 1072551 & 32609 & 268 & 1105428 \\
\hline Cultivated land & 0 & 0 & 0 & 0 & 437701 & 0 & 437701 \\
\hline Grassland & 0 & 0 & 0 & 60 & 566 & 31378 & 32004 \\
\hline
\end{tabular}


Table 4. Conversion Cost Matrix of Land Use in Sanya City from 2013 to 2017.

\begin{tabular}{lllllll}
\hline Land use types & Construction land & Unused land & Water zone & Woodland & Cultivated land & Grassland \\
\hline Construction land & 1 & 0 & 0 & 0 & 0 & 0 \\
Unused land & 1 & 1 & 1 & 1 & 1 & 0 \\
Water zone & 0 & 0 & 1 & 0 & 0 & 0 \\
Woodland & 0 & 0 & 0 & 0 & 1 & 1 \\
Cultivated land & 0 & 0 & 0 & 1 & 1 & 0 \\
Grassland & 0 & 0 & 0 & 0 & 1 \\
\hline
\end{tabular}

Table 5. Precision Meaning of Kappa Index.

\begin{tabular}{lll}
\hline Range of Kappa index & Consistency description & Accuracy of experimental simulation results in this study \\
\hline$[0,0.2]$ & Very low consistency & \\
$(0.2,0.4]$ & General consistency & Kappa $=0.890365$ \\
$(0.4,0.6]$ & Medium consistency & highest consistency \\
$(0.6,0.8]$ & High consistency & \\
$(0.8,1]$ & highest consistency & \\
\hline
\end{tabular}

Remarks: Kappa index ranges from-1 to 1, and the larger the value is, the better the consistency between the simulation results and the actual results is, and the value is mainly distributed in $(0,1)$.

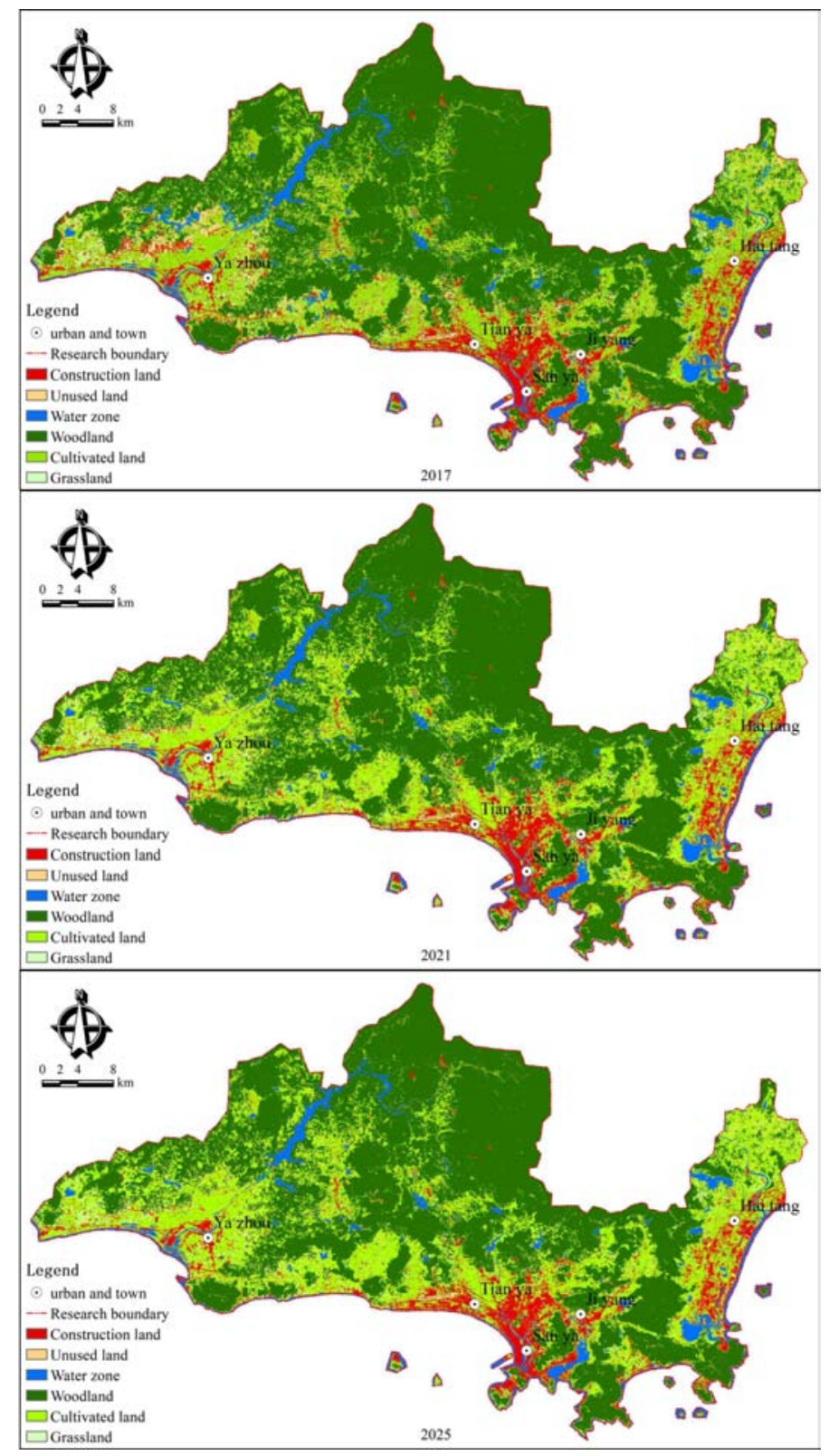

Figure 7. Simulation results of the spatial distribution of land use in 2017, 2021 and 2025. 


\subsubsection{Simulation Results}

The simulation results of this study fully consider the land use policy of Sanya City, developed a specific land use conversion cost matrix and domain weight, in order to achieve the purpose of vertical simulation of land use change trend in Sanya City. It can be seen from the simulation results that the overall pattern of land use in Sanya is very stable, and woodland has always played an important role in ensuring the ecological security pattern of the city. The dispersion of cultivated land is obvious, the expansion effect of construction land is weak, and the number of Unused land is significantly reduced (Figure 7).

\subsection{Dynamic Analysis of Land Use Change}

\subsubsection{Analysis of Land Use Transfer Direction}

During 2017-2025, the total land change in Sanya was $23.11 \mathrm{~km}^{2}$, accounting for $1.19 \%$ of the total area of the study area. Among them, the total area of cultivated land resources increased, and the total area of other five land use types decreased. From the conversion direction of land types, the specific features are as follows:(1) The woodland space continues to maintain the ecological security barrier function in Sanya, while the construction land conversion to agricultural land phenomenon is obvious. (2) Although cultivated land resources are guaranteed, the role of returning farmland to forest is far less than the occupation of forest land space. The increase in demand for arable land is 3.92 times as large as the area of returning farmland to forests, but the area of destruction by human activities is $2.73 \mathrm{~km}^{2}$. (3) The spatial expansion ability of agricultural land is strong, and the spatial expansion of cultivated land, woodland and unused land is the main land type of water space erosion. Water ecological environment is facing the threat of encroachment of cultivated land, woodland and unused land. The total water space decreased by about $9.40 \mathrm{~km}^{2}$, accounting for $40.68 \%$ of the total land use change. (5) The transfer of construction land reflects the determination of regional development to protect non-construction space land. About $5.7 \mathrm{~km}^{2}$ of construction land is transferred to woodland, which to some extent makes up for the encroachment of farmland on woodland space. (6) Unutilized land transfer forms have the role of promoting agricultural production. The vast majority of unused land is converted into arable land from the data, indicating that the land type has been better applied in rural areas (Table 6, Figure 8).

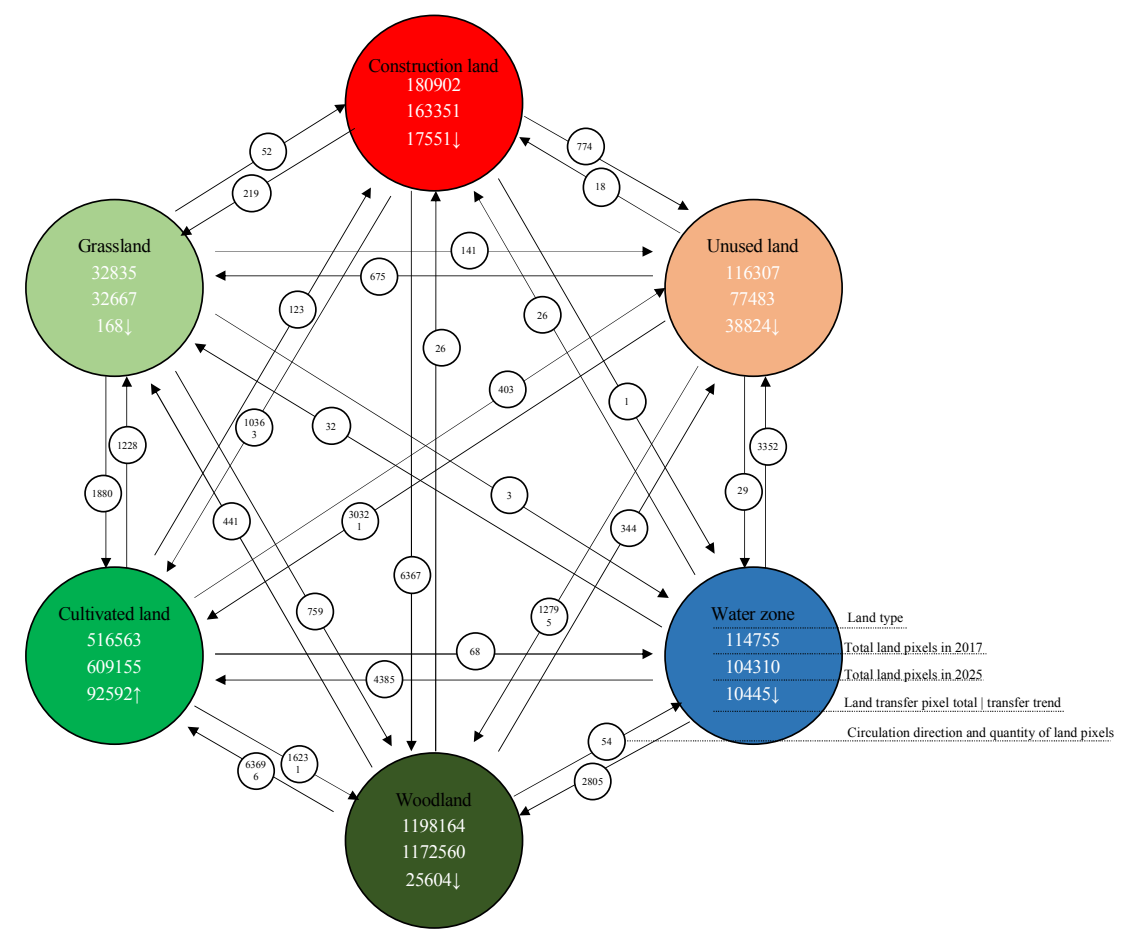

Figure 8. Direction of pixel transfer of land use in Sanya City from 2017 to 2025.

Table 6. Pixel Conversion Matrix of Land Use Types from 2017 to 2025.

\begin{tabular}{llllllll}
\hline Land use types & Construction land & Unused land & Water zone & Woodland & Cultivated land & Grassland & total \\
\hline Construction land & 163106 & 774 & 1 & 6367 & 10363 & 291 & 180902 \\
Unused land & 18 & 72469 & 29 & 12795 & 30321 & 675 & 116307 \\
Water zone & 26 & 3352 & 104155 & 2805 & 4385 & 32 & 114755 \\
Woodland & 26 & 344 & 54 & 1133603 & 63696 & 441 & 1198164 \\
Cultivated land & 123 & 403 & 68 & 16231 & 498510 & 1228 & 516563 \\
Grassland & 52 & 141 & 3 & 759 & 1880 & 30000 & 32835 \\
total & 163351 & 77483 & 104310 & 1172560 & 609155 & 32667 \\
\hline
\end{tabular}




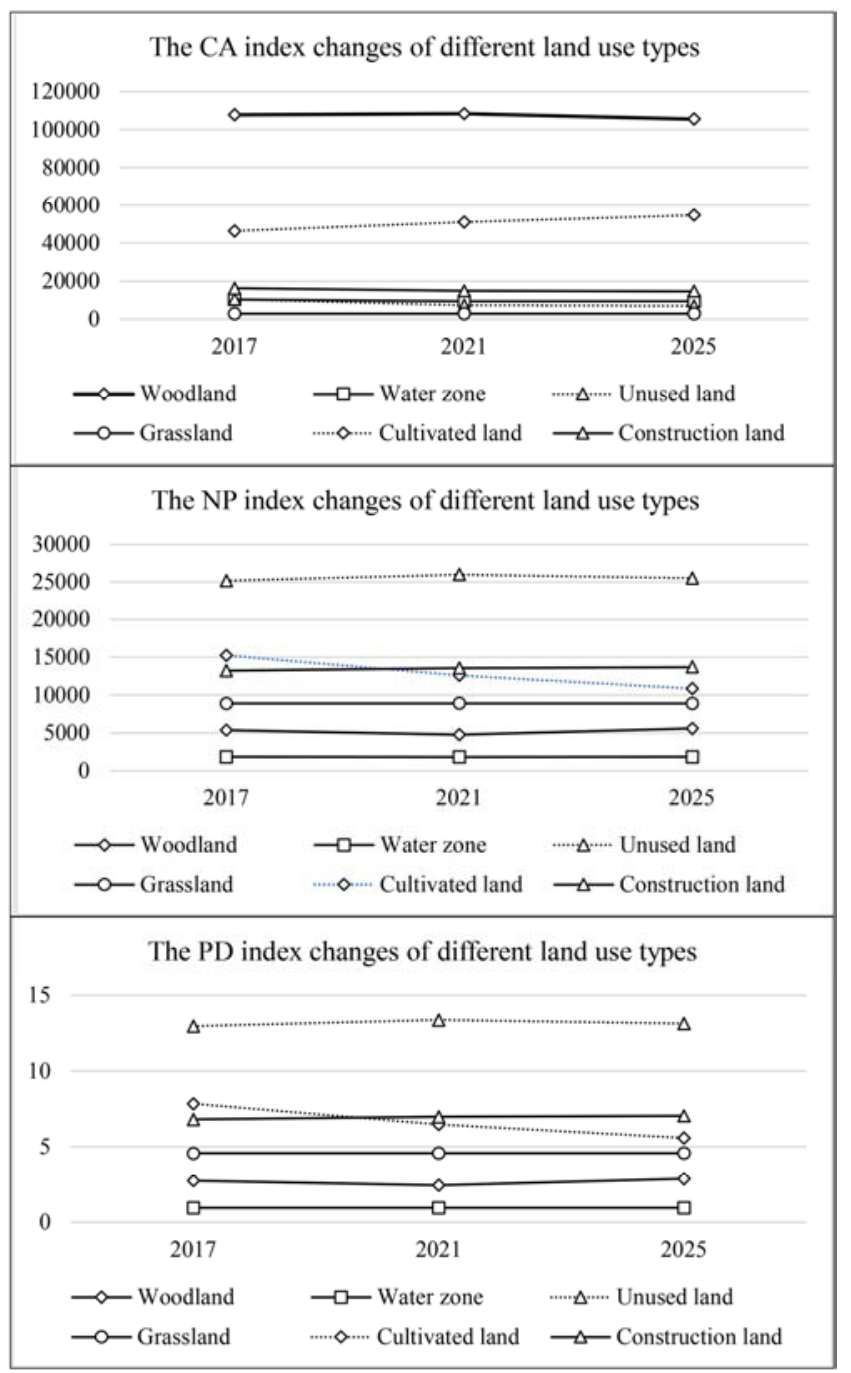

Figure 9. Trend of fragmentation index of different land use types.

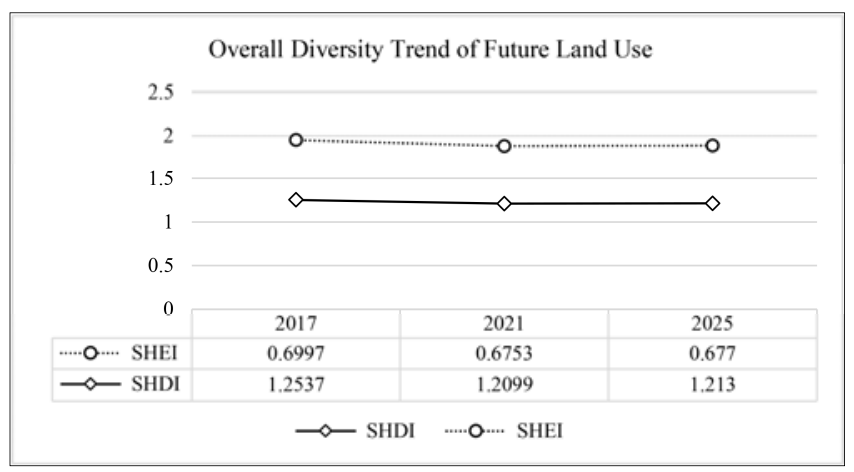

Figure 10. Diversity of Land Use Change in Sanya City from 2017 to 2025.

\subsubsection{Trend Analysis of Land Use Fragmentation}

The spatial distribution density of different land use types can reflect the degree of fragmentation, which is the direct embodiment of intensive and efficient land use. On the one hand, from 2017 to 2025 , the number of patches of land use in Sanya were 69783, 67693, and 66456, respectively, and the patch densities were $35.9045,34.8291$, and 34.1927 . The degree of fragmentation showed a slow decreasing trend, that is, the overall performance of the land system Integrity is enhanced. On the other hand, from the perspective of land use types, the degree of land use fragmentation in Sanya City in 2017 was ranked as: unused land-cultivated land-construction land-grassland-woodland-waters zone; In 2025, the degree of land use fragmentation in Sanya is ranked as: unused land-construction land-cultivated landgrassland-woodland-water zone. Its specific performance has 5 characteristics. There are six specific phenomena. Firstly, in addition to the water space, the area index of woodland is the highest, with the lowest patch number index and patch density index, and the fragmentation trend is significantly weakened, with absolute ecological security advantages. Secondly, the area index of cultivated land increased obviously, the quantity index of patch and the density index of patch decreased obviously, the fragmentation degree of land decreased obviously, and the integrity increased. Thirdly, the area index of unused land decreased while the number of patches and patch density increased significantly, the degree of dispersion of unused land in the study area strengthened; Fourthly, the fragmentation degree of water space is the lowest, the integrity is the strongest, and the spatial distribution is relatively stable; Fifth, the integrity of construction land is significantly enhanced and more complete, but its own decentralized layout determines the degree of fragmentation is higher than woodland and waters zone. In addition, unused land has the highest degree of fragmentation (Figure 9).

\subsubsection{Trend Analysis of Land Use Diversity}

In the next few years, the change trend of land use in Sanya can affect the spatial pattern within the land system to some extent, and the change conditions of land use are mainly limited in the simulation process. There are two main: one is to strictly implement the local land use policy, which is also the key to determine the sustainable development of regional land use; 2 is to formulate strict land use conversion matrix, and the restriction of land use circulation direction can guarantee the stability of ecological red line and the retention of farmland system to a certain extent. Based on this premise, the researchers found through simulation experiments: from 2017 to 2025, the diversity index and evenness index of the land system in Sanya were relatively stable, and the structure, function and ecological process of the ecosystem were relatively stable, which was conducive to promoting the sustainable development of the global Sanya ecosystem (Figure 10).

\section{Discussion}

\subsection{Follow the Planning Control of Territorial Space}

The spatial distribution of land use is the manifestation of the overall pattern of land space. Reasonable and scientific land space planning is conducive to regional sustainable development. As a constituent element of land system, the composition and distribution of land use type play an important role in regulating the internal structure and function of land system. Its essence is 
the analysis and guidance of land use mode and form. In this study, the simulation analysis of land use change is to predict the form, method and change trend of land use, which can provide a scientific reference for the planning of 'three areas and three lines' of land space planning. The distribution of land types in space is the result of land use and development. The change of different land use types has different probability of suitability distribution in space. Therefore, with the opportunity of land space reform, researchers strictly implement the "three zones and three lines" determined by land space planning, and control the impact of non-natural driving factors such as population, economy and society on land use change.

\subsection{Optimizing Landscape Pattern of Land System}

(1) Structural Regulation. The spatial pattern of land was optimized by 'matrix-corridor-patch' model. Maintain the ecological security barrier function of forest land landscape, make it give full play to the ecological background function of matrix elements, continue to maintain the ecological wetland and mangrove ecological effect of water corridors such as rivers and coastal zones, strengthen the ecological security protection of important traffic road corridors and the construction of animal and plant activity channels, increase the ecological circulation guidance of patch land space, and protect the ecological function effect of point ecological patches. (2) Functional Regulation. To guide urban land ecosystem expansion by land space control. The purpose of land spatial control is to ensure the functional integrity of the land system, and strictly comply with the 'three areas and three lines' spatial control scope is the fundamental method to comprehensively improve the regional land use diversity. (3) Guidance of dynamic process. Enhance the integrity of land landscape by reducing the density of land landscape patches. Through the transfer of land types, the land space with high fragmentation degree such as plain, platform and urban fringe area is reduced, and the patch area of various types of land is increased and the patch density of land is reduced in the form of weakening the decentralized layout of land, so as to improve the ecological process of land system and enhance the diversity and uniformity of land ecosystem.

\subsection{Controlling the Direction of Land Use Transfer}

The optimization of land use space can be controlled and guided by land circulation. Firstly, stabilize and enhance the ecosystem stability of woodland, reduce the fragmentation of landscape. By reducing and cutting down the human activities that destroy the stability of the land ecosystem, the grassland in the retreating platform and hilly areas is forest land, gradually reducing the area and quantity of non-forest land space patches in the whole hilly and platform areas, and enhancing the stability of the woodland boundary ecosystem. Secondly, the full development and construction of urban space inside and outside the unused land, reduce urban and rural construction activities on the ecological and agricultural space expansion. Priority should be given to the development of unused land landscape within the city and in the urban fringe areas, to restore the ecological effect of unused land landscape within the boundary of forest land and the scope of basic farmland protection areas, and to strictly control the expansion effect of urban and rural construction development. Thirdly, control the boundaries of urban space and the expansion of construction land, and improve the land utilization of space development. Under the premise of not breaking the boundary of urban development, adhere to the road of sustainable development, reasonable allocation of ecological land system in urban space distribution and ecological service ability, strengthen the stability of urban ecosystem, improve the quality of urban space living environment. Finally, to stabilize the spatial distribution of agricultural production and living areas, reduce the interference intensity of forest landscape boundary area.

\section{Conclusion}

Compared with most of the research results in China, this study realized the diversity change analysis of the horizontal land system ecological development level and the spatial distribution change trend of the vertical temporal level, which is also the original intention of this study. There are two specific characteristics: (1) In China, land use change driven by different factors is the main concern of most scholars, which is keen to simulate different development models of land use; (1) The land system itself is ecological. The author applies the landscape pattern analysis method to the development analysis of the land system, which is actually an attempt to study the land ecology.

Through the simulation and analysis of the trend of land use change in Sanya from 2017 to 2025, it is not difficult to find that under the strict restrictions on land use conversion, the fragmentation degree of the land system in Sanya has generally declined, and it maintains a relatively stable diversity and uniformity of the land system, reflecting the importance and necessity of constructing and improving the land use conversion system and system. Based on this, this study draws three conclusions: (1) Land use change is the root cause of the transformation of land use structure and function in Sanya City. Establishing scientific and reasonable land use transformation system is an important means to realize the sustainable development of land use. (2) Human activities are the main reason for the encroachment of forest land space and water space. Controlling the influence intensity of agricultural activities on agricultural space is the basic method to enhance the integrity of land system. (3) Land use change is the result of the change of land use landscape pattern. It is an effective way to improve the structure, function and dynamic process of land system to use 'patch-corridor-matrix' model to regulate the landscape pattern of land use.

\section{Foundation}

Sponsored by the Key Project of Teaching Reform Research in Colleges and Universities in Hainan Province (HNJG2019ZD-24). 


\section{References}

[1] Zhou H., Lei G. P., Zhao Y. H., et al. Based on CA-Markov model, land use dynamic simulation of Naoli River Basin [J]. Journal of Ecology and Rural Environment, 2016, 32 (2): 252-258.

[2] Zhang B., Lei G. P., Zhou H, et al. Based on CLUE-S model of mining city land use pattern scenario simulation [J]. Soil and water conservation research, 2016, 23 (5): 261-266.

[3] Peng Y. F.. Land use optimization simulation of metropolitan area based on FLUS model--Taking Shenzhen as an example [J]. Land and resources of Shandong, 2019, 35 (8): 70-74.

[4] Tian Y. C., Huang Y. L., Bai X. Y., et al. Land Use Change and Simulation of Tongzi River Basin Based on Binary Logistic Model [J]. Science and Technology and Engineering, 2019, 19 (6): 50-62.

[5] Zhao X. Q., He W., Li Z., et al. Land use simulation in rapid urbanization area--Taking Deyang City as an example [J]. Journal of Southwest Normal University (Natural Science Edition), 2020, 45 (7): 78-89.

[6] Gu L. Y., Zhang Y. H., Zhu X. Q., et al. Based on remote sensing and CA-Markov model of land use landscape pattern simulation and driving force research [J]. Journal of Engineering, Heilongjiang University, 2017, 8 (2): 14-20, 30.

[7] Zhang Z. P., Tan E. S., Yu Y., et al. Based on the simulation study of suburban land use under the background of urbanization--Taking Huadu District of Guangzhou City as an example [J]. Introduction of land and resources, 2017, 14 (3): 85-91.

[8] Chen Z., Fu W. C., Huang Y. B., et al. Based on Logistic-CA-Markov model of land use evolution and simulation in Fuzhou [J]. Journal of Anhui Agricultural University, 2018, 45 (6): 1092-1101.

[9] Yang J. X., Gong J., Li J. F. Based on LSSVM-CA model of complex land use change simulation-Ezhou City as an example [J]. Resources Science, 2016, 38 (8): 1525-1537.

[10] Zhang H. B., Gao Y., Cui Y. Z. Multi-scenario simulation of land use in typical agro-pastoral ecotone based on sandstorm control [J]. Environmental science research, 2019, 32 (6): 1081-1089.

[11] Hao X. J., Zhang H., Xu X. M., et al. Evolution and simulation of land use patterns in northern Shanxi [J]. Ecology, 2020, 40 (1): 257-265.

[12] TIAN T. Y., LI B. S. Urban land use pattern optimization simulation research based on the perspective of objective constraint--taking Hohhot as an example [J]. China Agricultural Notification, 2019, 35 (9): 86-94.

[13] Ruan J. J., Su J. H., Huang Y. C., et al. Simulation study on spatial-temporal pattern of land use in Qingpu District, Shanghai $[\mathrm{J}]$. China Agriculture Report, 2018, 34 (3): 112-119.

[14] Cao Q., Zhang P. L., Li W. Q., et al. Land use change analysis and time-space dynamic simulation [J]. Journal of Applied Sciences, 2017, 35 (3): 337-345.

[15] Li X. J., Shi S. Q., Cai W. M., et al., based on CA-Markov model to simulate land use change in Tianjin Binhai New Area $[J]$. Journal of Guangxi Normal University (Natural Science Edition), 2018, 36 (3): 133-143.

[16] Gong W. F., Wang X. X., Cao K. H., et al. Study on Land Use Change and Simulation Based on RS and GIS in Wuchang City $[\mathrm{J}]$. Journal of Engineering, Heilongjiang University, 2019, 10 (2): 15-22.

[17] Hu Z. N., Li Xin, Lou S. Y., et al. Multi-Scene Simulation and Realization of Land Use Structure in Yangzhou City Based on System Dynamics Model [J]. Soil and Water Conservation Bulletin, 2017, 37 (4): 211-218.

[18] He L., Jia Q. J., Li C., et al. Land use pattern simulation based on ecosystem service value and ecological security pattern [J]. Journal of Agricultural Engineering, 2016, 32 (3): 275-284. 